2. The spring is a round or wire spring instead of a flat one. The advantage of this is, that its diameter being the same in every direction it can be moved with almost equal facility in every direction. Thus the pads can be moved, not only towards or from each other, (like a pair of sugar tongs,) but if one be fixed the other can be moved up or down, or even in a circle. And, accordingly, when the truss is carefully applied, the back pad may be moved up or down to the extent of two inches, or even more, without disturbing at all the front pad in the groin; and it is found that it is always the back pad which is affected by any sudden movement of the body. This substitution, therefore, of a round, for a flat spring, confers an amount of selfadjusting power, sufficient to render any joint between the spring and the pads unnecessary.

3rd. There is no pressure upon or within two inches of the spinous processes. And not only is this avoided by slightly curving the posterior half of the instrument, but by thus crossing the median line both before and behind it, it obtains so firm a hold upon the pelvis as to render any strap or fastening between the two ends of the spring unnecessary, except in cases of extreme emaciation.

4. Even the double truss, as already stated, leaves one hip free.

It should have been stated that pressure upon the abdomen is as scrupulously avoided as upon the spine, the curve of the anterior half of the instrument being carefully adapted to the shape of the wearer, and the more powerful the pressure required, the more loosely is the truss made to fit round the pelvis ; in this respect it is just the reverse of the majority of trusses, in which the pressure is increased by tightenimg the straps and compressing all the parts surrounded by the instrument.

The following cases will $I$ think suffice in the way of illustration:-

Case 1.-H. Langford, aged 73, became the subject of a left inguinal hernia, thirty-five years ago, neglected it, and it soon descended into the scrotum. Has had trusses from every society in London, some of them very powerful, and with every variety of straps and fastenings, but for the last thirty years it has been constantly in the scrotum, except at night. When he first applied to me, it was of great size, completely filling half the scrotum, and had become to all intents and purposes direct; the points of two fingers could be passed through the ring apparently straight into the abdomen. There was also a small right inguinal hernia. He has now worn one of Newson's double trusses for nearly two years, and it has been only upon some very unusuai exertion, in unloading vans, \&c., that his hernia has escaped. The most violent coughing seldom or never produces any effect. The parts, too, have so contracted, that the hernia cannot now be made to descend to anything like the same extent as at first, even when the truss is removed.

Case 2.-Anne Sallaway, aged 45, has had a femoral hernia for the last eight years; it was small at first, but soon increased in size. She had two trusses from the society in Hatton Garden; neither, however, were of the slightest use. Four years ago it became strangulated, and she was operated upon in Guy's Hospital by $\mathbf{M r}$. Bransby Cooper. After the operation it became larger than ever, and after repeated attempts to obtain an efficient truss from the two well-known instrument makers at the west end, she gave it up in despair. When I first saw her the hernia was of the size of a small apple, and the crural aperture admitted the point of my thumb for nearly an inch. The only difficulty met with was in avoiding pressure upon the hip, owing to a peculiarity in the shape of her pelvis. The hernia was completely retained from the first, and is now so much reduced in size as to require but very slight pressure.

Case 3.-J. G., aged 46, admitted into University College Hospital under Mr. Quain for hydrocele. The following was the report on his admission:- "Scrotum as large as a full-sized hat, twenty-one inches in circumference, and at its upper part the hydrocele is covered largely with bowel in a hernial sac." He was tapped three times. At the first operation seven, at the second four pints, and at the third one pint, were drawn off. The following was the report when he was discharged :- "There is no deformity; the scrotum on the whole is larger than natural," \&c., \&c.; "the bowel, which had been almost constantly during several years in the scrotum, is now retained in the abdomen with one of Newson's wire spring-trusses." When this man was first sent to Mr. Newson by Mr. Quain, his case was unusually embarrassing, owing, not only to the great size of the ring, but the distortion of the parts, which had not yet subsided.

Clapham, Surrey, May 3, 1851.

\section{ON THE A.FRICAN FEVER.}

\section{BY HENRY LANDOR, Esq.,}

IATE COLONIAL SURGEON TO THE GOLD COAST.

THE opinions of nearly all medical men who have practised in hot countries seem to be against the contagion of fever, whether it be called plague, or cholera, or yellow fever, or the African variety of the disease. These opinions, and the practical results to which they lead, are admirably condensed in the " Report or Quarantine," issued by the Board of Health, and printed by the authority of Parliament.

It seems, also, to be the general opinion that there is only one fever poison, and that local or atmospherical circumstances determine the type the disease will assume in each epidemic. In the present state of our knowledge it is impossible to determine what these local circumstances are with sufficient exactitude to guide the sanitary practitioner; but it is somewhat easier to find out what they are not; and the considera- 
tion of the negative may eventually lead us to the knowledge of the positive. We all admit the influence of dirt, famine, and want of ventilation in increasing the virulence of every epidemic. We likewise have an impression that fevers of the intermittent variety, in particular, owe their severity, if not their origin, to decaying vegetation. It is my object to bring forward some facts to show that this is by no means the case, and that if decaying vegetation encourages the ravages of the epidemic, it is exactly in the same manner that filth, famine, and want of ventilation do the same, and not as the cause of its origin. The poison of fever arises from some general cause not yet known. The circumstances that favour its distribution are more within our present means of observation, and when these are accurately determined, the true origin of the disease will be more easily discovered.

I purpose in this paper to give some account of the African fever as it is known on the west coast. It prevails within the warmer latitudes from the desert on the north to the borders of the Cape Colony. It is as fatal in the Gambia, at Sierra Leone, as at Cape Coast Castle, or at Bagagry; yet the physical circumstances of the country widely differ at all these points. From Cape Palmas to Cape St. Paul, which includes the Gold Coast, the geological formation is the primitive, stratified, the usual formation of gold deposits. This formation is necessarily the driest of all the geological series, for it is exceedingly porous, and hardly capable of retaining water on its surface. In countries of this formation, if situated in warm latitudes, the rivers rarely, if ever, run all the year. The rivers are mere surface drains, and carry off only the surplus of excessive rains ; consequently, when the wet season departs, general dryness prevails. Now this is the state of things from Cape Palmas to Cape St. Paul. There are no rivers broader than the Thames at Windsor, no extensive marshes, no mangrove swamps, and yet the African fever prevails as extensively and is quite as fatal as it is in the wettest part of the coast. No decomposing vegetation exceeding that of the average of DRY tropictl countries prevails to countenance the opinion that such is the origin of the disease. On the contrary, the surface of the country is not covered with thick herbage or decaying leaves, nor is the soil of that deep loamy character, resulting from vegetation, which characterizes the interior of the Brazils; yet the latter is free from fever, while the former is infected with it. On the Gold Coast the disease generally puts on the inter:nittent character markedly, yet in what are called bad seasons it becomes remittent, and in most of the rapidly fatal cases is continued; and occasionally even it assumes the appearance of yellow fever, with the coffee-coloured vomit and a yellow skin, and a fatal termination in three or five days. It is supposed to be extremely fatal once in seven years, when the mortality is generally $\mathbf{5 0}$ per cent., often more, while in ordinary years it seldom exceeds 25 per cent. However, it is not my object to describe the fever, but to show that it is not dependent on vegetation. The mortality on the Gold Coast is not exceeded on any part of the coast ; it is not greater at the Gambia, where vegetation is denser, nor at Sierra Leone, where the Bulam shore, a region of swamps, is supposed to cause it, nor at that part of the coast from Cape St. Paul to the Calabar, which includes the whole delta of the Niger. Now surely this ought not to be if the general opinion were the correct one.

Moreover, when I was at the Cape de Verdes in 1841, the islands were suffering severely from fever of this very African type, consequent on a famine of great severity, such as, but more than that, which now prevails in the island of San Nicolas amongst the same group. But mark ! the famine was caused by a drought of many months' duration, and the fever accompanied this state of things; but if decaying vegetation were the cause, it should have arisen after an extremely wet season, not a dry one. In the whole island of St. Jago there was not herbage enough to feed the miserable lot of cattle and goats that had survived the drought, and the inhabitants were keeping them alive on the succulent stems of the plantain. The island is a mass of volcanic scoria, with a few cocoa-nut and tamarind trees, and bananas in the valleys; and I was taken to a valley to see one poor wretched stream of water, about a yard across, which was exhibited as a curiosity, and which, after running a mile or two, lost itself in the scoria. Surely this is not the state of country generally supposed to cause fever, but the reverse. The acting Consul, (the Consul himself having the fever, and having gone to a more westerly island for improvement,) told me that his father had removed to be farther from the African coast, the proximity of which he supposed had caused the fever in St. Jago ; but this is obviously a mistake, as the opinion of every medical man em. ployed in the squadron is, that forty miles from the coast of Africa the crews do not become infected with fever, and this opinion caused Sir Charles Hotham to order his vessels to keep about that distance at sea. (See his evidence.) The most easterly of the Cape de Verdes is many hundreds of miles from Africa, and I am convinced that Africa had no more to do with the origin of fever in those islands than England had; in fact the fever-poison, however, that may arise, found in the islands themselves favourable circumstances for its development, and fever succeeded, as it always does succeed, famine and privation, whether in the Cape de Verdes or in Ireland. The local circumstances of the islands favoured it, as no place exceeds Porto Peaga in filth ; indeed, bad houses, dirt, and bad feeding, were common to the whole island, and are the characteristics of Portuguese habitations in Africa and in the Brazils. The wonder is, not that fever prevails, but that it is ever absent. No one acquainted with African towns can fail to perceive the abundance of dirt within them; no drains, abundance of cess-pools, no privies, and crowded habitations, and probably, more than all, the pernicious custom of burying the dead under their houses, are all most suitable provocations of pestilence. Every African family bury their dead beneath the lower floor of the family house. If church yards are evils in a city, what would be the condition if the dead of each 
house were superficially buried beneath the kitchen floor?

The circumstances here detailed--the prevalence of fever in dry countries equally as in wet-prove, I think, that whatever may be its source, decomposing vegetation is not that source, and show that, although decomposition may be favourable to its development, it is so in just the same manner as dirt, famine, or want of ventilation.

Time may make us acquainted with the changes in the atmosphere produced by electricity and other subtle agents, and explain to us the laws of such changes, then we may see the reason of the periodicity of fatal seasons at present concealed from us. Our knowledge is not sufficiently advanced to enable us to discern these things now; but it is much and useful, as $I$ said at the commencement, to find out what is not correct, for displacing an erroneous opinion is a great step towards attaining a true one.

I may add as a corroboration, that in Western Australia large and extensive swamps abound, and much mangrove muddy country, yet no one ever heard of a virulent fever; and Europeans are constantly in the habit of sleeping near such swamps, but they never have fever.

Heigham Retreat, Norwich, May 10,1851 .

\section{CURIOUS TRAIN OF SYMPTOMS CONNECTED WITH A CLOT IN THE MIDDLE LOBE OF THE CEREBRUM.}

By H E R Y C O O P R, Esa., Lond., PHYSICIAN TO THE GRNBRAL INYIRYARY, HOLL.

\section{To the Editor of the Provincial Medical and Surgical Journal.}

Sir,-The following case has been one of great interest to the medical men in charge of it during its long and painful progress; if you think it will be so considered by your readers, it is very much at your service. The case is remarkable as shewing the variety and importance of diseased actions which may result apparently from the same cause, such diseases, though varying in seat and intensity, still maintaining the same general congestive character.

The subject was a lady, 35 years of age, of spare habit, active, intelligent, and of exciteable temperament. She had borne several children, and enjoyed good health, but for the last few years had undergone much anxiety and fatigue in nursing. In the winter of $1848-9$ she was knocked down by a carriage and sustained some injury of the head. In the autumn of 1848, she had a severe attack of the malignant cholera then fatally prevalent. She rallied from the congestive stage of this disease and made a satisfactory convalescence. An attack of epistaxis occurred in Jauuary, 1850. In the spring of 1850 she was suddenly attacked with epileptic coma, while still subject to much harass of mind and body. The seizures which I witnessed at a later period of the illness, commenced with convulsion, coming on much as in ordinary epilepsy, generally with little or no warning; they continued three to five hours, and were so violent and long continued as to threaten to destroy life either by asphyxia or exhaustion of vital power. The means used exercised little control over the paroxysm till its usual term of five hours had expired, when the patient sunk into a deep and unrousable torper. In twelve to twenty-four hours this state was succeeded by delirium of a wild character, not unlike delirium tremens, accompanied with wakeful nights ; after which a long deep sleep put an end to the attack, and extreme prostration and partial amaurosis of the right eye alone remained. The whole attack would last four or five days. The paroxysms occurred at variable periods of three or four weeks.

In November, 1850, this lady's life was further placed in jeopardy by epistaxis, which had gone on to a frightful extent before assistance arrived. Plugging of the posterior nares and the most careful restorative measures brought her through this danger, and it was hoped that an immunity had thus been ensured against the cerebral attacks.

In the early part of December we were surprised by another seizure equally violent and sudden with those which had preceded, but in a totally different seat. This was spasmodic asthma with intense dyspnœa, deep congestion, and sudden œdema of the superior extremities. From this desperate condition she again rallied, but there remained some dyspnœe, copious expectoration which became rusty, frequent spasmodic gasps in the breathing, and a dull impermeable patch in the back of left lung. During the whole of this time her intellect remained clear, though she manifested irritability and peculiarities of temper not natural to her.

We now come to the last phase of this long course of suffering. While slowly recruiting from the congestive attack on the lungs, she had one evening a convulsive paroxysm, of much less than usual severity, and in the morning was found paralytic of the right side. From this state she also slowly recovered, but the powers of life were now worn out with the long struggle; her mind became fatuous, with occasional maniacal delirium, and she died seven days after the last attack, and eleven months after the first epileptic seizure.

The post-mortem examination showed very great congestion of the external vessels, of the scalp, and of the scull and its membranes. The blood was fluid, and ran from the incisions in a stream. The brain was firm and healthy, and not unnaturally vascular; nor did it present any unusual appearance till the middle lobe was sliced, when a solid, firm, palish, fibrinous clot, surrounded with a discoloured margin, was found imbedded in the white matter under the thalamus of the left side ; it was of an irregular oval shape, one inch long, by somewhat less than half an inch broad, its long axis looking upwards and forwards. There was little fluid in the ventricles. The plexus was pale, but the arteries at the base of the brain was somewhat thickened. The lungs were somewhat œdematous. The heart was 